\title{
Caballeros centroeuropeos en España y Portugal durante el siglo XV
}

Antonio Antelo Iglesias *

Entre las fuenies históricas de muy vario interés - según el talante, la educación o los fines perceptibles en cada escritor- se hallan, como es sabido, los relatos de viajes y peregrinaciones. J. Richard, en una ponderada introducción al estudio de esos textos, define y caracteriza el género, fija su tipología, propone las reglas de crítica y, por último, aquilata su valor histórico ${ }^{1}$. Bajo el epígrafe «Exploradores y aventureros» agrupa diversos testimonios que, en ciertos casos - nobles o burgueses-, representan genuinas experiencias «turísticas". «El número de laicos - dice - no cesa de aumentar desde comienzos del siglo XIII, ya sean caballeros como Joinville, Schiltberger, Lannoy o La Broquière, ya

* UNED. Departamento de $\mathrm{H}_{.}{ }^{\mathrm{a}}$ Medieval, $\mathrm{H}{ }^{\mathrm{a}}$ Moderna y Ciencias Historiográficas.

J. RICHARD: Les récits de voyages et de pèlerinages, Turnhout (Belg.) 1981 (Fasc. 38 de la Typologie des Sources du Moyen Age occidental, dirig. por L. Génicot). Vid. también: R. FoulCHE-DELBOSC: Bibliographie des voyages en Espagne et en Portugal, "Revue Hispanique», III (1896), 1-349. Reprod. en facs.: Amsterdam, Meridian Publishing Co. 1969.- A. FARINELLI: “Viaggi e viaggiatori nella Spagna e nel Portogallo", Mélanges offerts à Emile Picot, vol. II, Paris 1913, págs. 583-633. Las referencias al siglo xv, en las págs. 583-590. Cf. la ed. española: Viajes por España y Portugal, desde la Edad Media hasta el siglo xx. Nuevas y antiguas divagaciones bibliográficas, 2. ${ }^{a}$ ed., Roma 1942 (Reale Academia d'Italia. Studi e Documenti, II, vol. I). 
mercaderes como Marco Polo, o aventureros como Nicolò de Conti» 2. En la Península lbérica el siglo XV ofrece numerosos ejemplos de nobles que acudian a ella, bien para medirse con los catalano-aragoneses o los castellanos en sonados pasos de armas, torneos y justas, bien para combatir al moro en Granada y África, orar ante el sepulcro del Apóstol en Compostela o, simplemente, correr mundo. Tres de esos caballeros, centroeuropeos, merecen aquí ser evocados: Jörg von Ehingen, Nicolás de Popplau o Popielovo, y Arnold von Harff ${ }^{3}$.

\section{CABALLERÍA E HISTORIA CULTURAL EN LA BAJA EDAD MEDIA}

Aunque el arte de la guerra iba socavando, cada vez más, el poder caballeresco, dicho estamento --por su código ético y su privilegiado status sociopolítico- descollaba aún vigorosamente en las posiciones rectoras de mayor influencia y responsabilidad, tanto por el culto al linaje

2 J. RichaRD, ob. cit., pág. 38. Sobre ésta y otras cuestiones, vid. los trabajos presentados al Colloque du CUERMA, 5-7 marzo 1976: Voyage, quête, pèlerinage dans la littérature et la civilisation médiévales, Aix-en-Provence 1976. Una obra de carácter general, todavía útil, es la de A. P. NEwTon: Travel and Travellers of the Middle Ages, ed. by...-, Londres 1926. Respecto a la Península lbérica, prestan aún buenos servicios por los resúmenes de algunos viajes importantes y la inclusión de pasajes, a veces extensos: M. BERNARDES BrAnCO: Portugal e os estrangeiros, 3 vols., Lisboa 1893-94-95, y J. Garcia MERCADAL: España vista por los extranjeros, vol. I (Relaciones de viajeros desde la edad más remota hasta el siglo xVI), Madrid 1919, sin aparato crítico.

3 Vid. los Viajes por España, de Jorge de Einghen, del Barón León de Rosmithal de Blatna, de Francisco Guicciardini y de Andrés Navajero. Traducidos, anotados y con una Introducción por D. Antonio M. Fabié. Madrid, Librería de los Bibliófilos, 1879 (colec. "Libros de Antañon, VIII). Pese a sus deficiencias, es de obligada consulta. Para J. von Ehingen, cf. págs. III-XVII y 1-46. En alemán ha sido editado por F. PFEIFFER: Des schwäbischen Ritters Georg von Ehingen Reisen nach Ritterschaft, Stuttgart 1842 (Bibliothek des literarischen Vereins, 1). Más accesible resulta la trad. de M. LETTS: The Diary of Jörg von Ehingen, Londres 1929.- - La única versión disponible, en español, del relato de Nicolás von Popplau o Popielovo (fragmentaria), se halla en el libro de J. LISKE: Viajes de extranjeros por España y Portugal en los siglos xV, xVI y xVIl. Trads. del original y anotados por F.R. Madrid, Casa Editorial de Medina, 1879, págs. 9-67. Se completará en algunos aspectos con J. Garcia Mercadal: ob. y vol. cits. (n. 2), págs. 99-108. - Sobre Arnoid von Harff, vid. E. von Groote: Die Pilgerfahrt des Ritters Arnold von Harff von Köln, Colonia 1860, y $L$. VAZQUEZ DE PARGA: «ltinerarios y relatos de viajeros», en: J. M. LACARRA, J. URIA y L. VAZQUEZ DE PARGA: Las peregrinaciones a Santiago, vol. I, Madrid, CSIC, 1948, págs. 227233. 
como por la riqueza de que solía hacer gala. No siempre, claro está, pues menudeaban los hidalgos rurales sin medios de fortuna para sostenerse a un nivel decoroso; y las escaseces que algunos sufrían, unidas al instinto depredatorio, explican la proliferación de "caballeros bandidos" que se da en la Baja Edad Media ${ }^{4}$. "Lo único - afirma J. Bühler-que en rigor se hallaba anticuado para aquellos tiempos, por lo menos en parte, era la manera exterior de comportarse la nobleza. No lo eran sus ideas ni sus funciones en la vida del Estado, que seguían manteniéndola a la cabeza de la sociedad" 5 .

J. Huizinga, en su clásico mural dedicado a Francia y Borgoña, pero asimismo en una penetrante conferencia de 1921, insistía sobre «la nostalgia de una vida más bella", el artificio del romanticismo caballeresco $y$, por tanto, la falsedad notoria de sus expresiones cortesanas ${ }^{6}$. Sin embargo, frente a la acentuación de los factores económicos introducida por la nueva historiografía, subrayaba que a través de las fuentes narrativas se aprecia cómo «la forma noble de la vida conservó su imperio sobre la sociedad mucho tiempo después de haber perdido la nobleza su preponderante significación como estructura social» ${ }^{7}$. Huizinga ponia de relieve, también, la contradicción entre el ideal estético y el ético de la Caballería, que fracasa - ante la moral cristiana, precisamente - por su origen pecaminoso, ya que «el núcleo del ideal sigue siendo la soberbia embellecida" ${ }^{8}$. No obstante, ese ideal llegó a tener un gran ascendiente

Cf., p. ej., J. BüHLER: Vida y cultura en la Edad Media, trad. espñ., México, FCE, 1946, págs. 164-167 y 173-175, especialmente. Las transformaciones en el arte de la guerra explicanlas, con gran rigor, entre otros: F. Lor: L'art militaire et les armées au Moyen Age en Europe et le Proche Orient, vol. I, Paris 1946, y Ph. ConTAMine: Guerre, Etat et société à la fin du Moyen Age. Études sur les armées des rois de France. Paris-La Haya 1972. Es asimismo valioso el artículo de S. DE Moxo: Ejército, diplomacia y finanzas como medios de acción del Estado en la Baja Edad Media, "Studium" (Bogotá), III (1959), 85104. Para los "caballeros bandidos" en la Península Ibérica, vid. S. Moneta VeLAYos: Malhechores feudales. Violencia, antagonismos y alianzas de clases en Castilla, siglos XIII-XIV, Madrid 1978. Debe agregarse el capítulo que al tema dedica E. SARASA SÁncheZ: Sociedad y conflictos sociales en Aragón. Siglos XIII-XV, Madrid. Siglo XXI, 1981, págs. 100-109.

5 J. BüHLER, ob. cit. n. 4, pág. 178 ,

- J. Huizinga: El otoño de la Edad Media, Estudios sobre las formas de la vida y del espiritu durante los siglos XIV y XV en Francia y en los Países Bajos. Trad. espñ. Madrid, Revista de Occidente, 1945, págs. 45-79. El tema de la conferencia (Société d'Histoire Diplomatique, 16-Vl-1921) es "La valeur politique et militaire des idées de chevalerie à la fin du Moyen Age y se publicó en la Revue d'histoire diplomatique", XXXV, 1921, 126-138. Vid. la trad. espñ. en: Hombres e ideas. Ensayos de historia de la cultura, Buenos Aires, Cía. Gral. Fabril Editora, 1960, págs. 173-182.

J. HuIZINGA: Otoño, págs. 81-82.

8 J. Hulzinga: Otoño, pág. 96. 
político: la creación misma del Estado de Borgoña, por ejemplo - surgido en la persona de Felipe el Atrevido, cuyo heroísmo en la batalla de Poitiers (1356) fue premiado así por su padre Juan II el Bueno-, se relaciona intimamente con la virtud, el honor, la nobleza y la gloria o fama, que el propio Huizinga estudió, comparativamente, en su magistral Homo ludens. "Una línea recta -expone- conduce del caballero al honnête homme del siglo XVII y el gentleman moderno. El Occidente latino ha incluido en este culto el ideal del amor cortesano, confundiéndolo en tal forma con él que la trama, a lo largo, ha ocultado el hilo» ${ }^{9}$.

M. Keene, si bien matiza y corrige hoy los supuestos del gran historiador holandés acerca de la Caballería, no disiente al examinar sus formas y contenido real durante los siglos XIV y $x \mathrm{~V}$ : votos solemnes, acciones militares, viajes. «El fuerte individualismo - reconoce- de la cultura caballeresca encontró la manera de expresarse en el ideal del caballero andante, que también dejó su poderosa huella en muchas actitudes europeas de los últimos tiempos» ${ }^{10}$.

Quizá más que otros Estados de Occidente -exceptuada Borgoñalos hispánicos se destacan por el esplendor, durante las últimas centurias medievales, de esas formas de vida caballerescas que, ya en su conjunto, ya monográficamente, han indagado M. de Riquer, J. Scudieri-Ruggieri, R. Boase, etc. ${ }^{11}$. La Península atraía, como era de esperar, por «el doble aliciente de las lucidas cortes de los reyes cristianos y la frontera

9. JuIZINGA: Homo ludens, trad. espñ., Madrid, Alianza Editorial, 1972 (LB 412), pág. 126. Un ensayo notable sobre esa tradición y sus cambiantes manifestaciones literarias en España, lo ofrece B. BLANCo-González: Del cortesano al discreto (Examen de una decadencia), vol. I, Madrid, Gredos, 1962. M. ${ }^{2}$ R. LIDA sometió, por su parte, a un exhaustivo análisis los textos en su clásico estudio La idea de la fama en la Edad Media castellana, México, FCE, 1952.

10 M. Keene: La caballería. Trad. espñ. Prólogo de M. de Riquer. Barcelona, Ariel, 1986, pág. 327. Por su rico material literario, historiográfico, jurídico-político, efc., esta síntesis es de primer orden; también, por el approach personal a una temática compleja.

11 Vid., sobre todo: M. DE RIQUER: Vida caballeresca en la España del siglo XV. Discurso de recepción en la Real Academia Española y contestación de D. Alonso. Madrid 1965, y Caballeros andantes españoles, Madrid, E. Calpe, 1967 (Colec. Austral, 1397). Cf. asimismo su trabajo "Andanzas del caballero borgoñón Jacques de Lalaing por los Reinos de España y los capítulos del siciliano Juan de Bonifacio», en: "Strenae». Estudios de Filología e Historia dedicados al Profesor Manuel Garcia Blanco, Salamanca 1962, págs. 393-406.- Otros dos panoramas excelentes son los de J. ScudiERI-RuggiERI: Cavalleria e cortesia nella vita e nella cultura di Spagna, Modena, STEM, 1980 (cf. especialmente las págs. 57-71 y 241-334), y R. BOASE: El resurgimiento de los trovadores. Un estudio del cambio social y el tradicionalismo en el final de la Edad Media en España. Trad. espñ. Madrid, Pegaso, 1981, págs. 57-67. 
con los moros, que forzosamente había de reavivar el espíritu de cruzada, $\tan$ vinculado a la caballería y a la literatura» ${ }^{12}$; siendo ostensible, además, una "ósmosis" entre la ficción y la vida real, pues "los caballeros, grandes admiradores de las novelas de aventuras y de las hazañas de sus héroes, quieren vivir como ellos", e, inversamente, «la novela caballeresca se inspirará en las actitudes novelescas de los caballeros reales" ${ }^{13}$.

Ahora bien, pese a las crónicas y al mundo cortesano, alzábanse ya en la Castilla del siglo XV autorizadas voces de crítica moralizante, por la decadencia o pérdida del nervio, al comparar algunos tratadistas la situación de su tiempo con la de antaño. Rodrigo Sánchez de Arévalo es, por ejemplo, uno de ellos: en la Suma de la Política (ca. 1454) se lamenta de los caballeros que "gastán más en una ropa o en un pequeño anillo que en todas sus armas; assí mesmo más gastan en guarniciones superfluas que no en la principal armadura, ca a las vezes trahen muy fermoso penacho y de gran valor, y trahen las armas de vil precio» ${ }^{14}$. También deplora el que ya no se juren "expressamente» la fidelidad a Dios y el celo por la honra de su Iglesia; la lealtad al Rey o príncipe sirviéndole y obedeciéndole con reverencia; la lucha, hasta la muerte, "por la salud de su rey y de la república", y, finalmente, el amparo de las viudas, de los huérfanos y de los débiles.

Poco después, en la segunda mitad del siglo, Mosén Diego de Valera denuncia, a su vez, tal profanación del código ético, a cuya observancia dirige el notable Espejo de verdadera nobleza, basado en el De insigniis et armis de Bartolo (ca. 1350). «Estonce - sentencia- se buscaba en el caballero sola virtud, agora es buscada cavallería para no pechar; estonce a fin de honrar esta orden, agora para robar en su nombre; estonce para defender la republica, agora para señorearla; estonce la orden los virtuosos la buscavan, agora los viles buscan a ella para aprovecharse de solo su nombre...” ${ }^{15}$.

12 Cf. M. DE RIQUER: Vida caballeresca en la España del siglo XV (cit. en la n. 11), pág. 19.

${ }_{13}$ M. DE RIQUeR: Caballeros andantes españoles (cf. n. 11), págs. 68-69.

14 Rodrigo Sánchez de ArÉvalo: Suma de la Política, ed. de J. Beneyto, Madrid, CSIC, 1944; cf. Libro I, Consideraciones XVI-XVIII, en particular las págs. 277-78.

15 Diego de VAleRA: Espejo de verdadera nobleza, en: Prosistas castellanos del siglo XV, ed. M. Penna, Madrid, Atlas, 1959, pág. 107 (Biblioteca de Autores Españoles, CXVI). 
La crisis política e institucional de Castilla y Aragón hasta el advenimiento de los Reyes Católicos, sus lacras morales de todo signo y condición, que las fuentes revelan copiosamente, afectarían sin duda al mundo caballeresco; el cual, no obstante, exhibe durante el siglo xV sus rasgos externos más fastuosos y cautivadores, en medio de la relajación social, atrayendo a numerosos aventureros europeos ávidos de galardones y de experiencias múltiples. Jörg von Ehingen es, acaso, el noble germánico de mayor relieve en este sentido, por lo que su testimonio merece recordarse.

\section{LA IMAGEN DE HISPANIA ALLENDE LOS ALPES}

Los que podemos denominar «turistas" alemanes sugieren otras perspectivas, no menos importantes.

S. Arnoldsson -investigador sueco prematuramente desaparecido cuando sus trabajos sobre los orígenes de la «Leyenda Negra» y la historiografía hispanoamericana del período colonial anunciaban contribuciones muy sólidas- Ilamó la atención, unos treinta años ha, en torno a los relatos de viajeros centroeuropeos por España y Portugal, tanto nobles como ùurgueses; vislumbres, según él, de un clima de opinión pública que, con anterioridad a la Reforma luterana, se iba gestando frente a los reinos hispánicos ${ }^{16}$. Aunque no se ocupa exclusivamente del mundo germánico, sino que aborda también la génesis, en Italia, de los sentimientos e ideas más o menos tendenciosos acerca de España, dedica luminosas páginas a los antecedentes centroeuropeos, entre los que figuran el barón León de Rožmithal, Nicolás de Popplau o Popielovo, Jerónimo Münzer y Arnold von Harff ${ }^{17}$.

No todas las experiencias y aseveraciones de los extranjeros mencionados - salvo el último-, más las de ciertos caballeros andantes, fueron negativas: hay en sus informes, como es natural, reminiscencias gratas e incluso laudatorias sobre los países visitados y sus gentes.

16 S. ARnOldsson: La Leyenda Negra. Estudios sobre sus origenes. Göteborg 1960 («Acta Universitatis Gothoburgensis». "Göteborgs Universitets Arsskrift», vol. LXVI, 1960-3).

$17 C f$. las págs. 110-117 y las notas correspondientes, págs. 199-201. 
Ahora bien, priman los juicios adversos y las situaciones embarazosas; especialmente cuando se trata de personajes aristocráticos, instruidos o acaudalados que, al comparar formas de vida y maneras de pensar o de sentir, formulaban críticas no siempre objetivas y profundas.

Así, prescindiendo ahora de los aspectos positivos, quizá predispusieron desfavorablemente a sus compatriotas otros rasgos poco halagüeños: falsía y avaricia, orgullo e ignorancia, rudeza e impertinencia, que Nicolás de Popplau señala como actitudes muy extendidas en los reinos hispánicos, junto con la inmoralidad y el mal servicio de las posadas. Arnold von Harff se quejará también de las incomodidades y explotación de los peregrinos; como, a su vez, los redactores del viaje de Rožmithal, Šašek y Tetzel, quienes abundan en acerbos comentarios sobre la inseguridad de los caminos, la violencia y la falta de hospitalidad, frecuentes sin duda en la Castilla de Enrique IV y el Aragón de Juan II. La vestimenta suntuosa, con "brocados de oro, telas de seda y otras de no menos valor», asombraba un tanto a Jerónimo Münzer ${ }^{18}$.

Lo que a todos impresionaba mayormente era el número de judíos, «marranos» y musulmanes, así como el tenor exótico, oriental, de la música y la danza, de la decoración de interiores, de la indumentaria, de la mesa, etc. A. Castro, citando al barón de Rožmithal, conviene al respecto en que «los modos del vivir morisco se habían infiltrado en la vida privada; mejor dicho, esos modos llevaban siglos siendo españoles, pero las gentes del siglo $x v$ han escrito sobre ello, porque en aquel tiempo ya se prestaba atención a lo que acontecía en torno al escritor, a lo contemporáneo, a la situación vital del hombre en un tiempo y espacio dados" ${ }^{19}$.

Los viajeros germánicos tomaban, además, buena nota del color de la piel y de los ojos: Gabriel Tetzel, por ejemplo, no repara solamente en detalles de la vida cotidiana, sino, ante todo, en que las "doncellas y señoras" de Burgos eran morenas y de ojos negros ${ }^{20}$. Para estos extranjeros, racial, social y aun espiritualmente no había diferencias esenciales entre cristianos y moros. En cuanto a los judíos y «marranos» -tan influyentes, según Nicolás de Popplau-, el testimonio de Münzer es ya otro; se refiere a los de Castilla y Aragón en pretérito- "eran antes

18 Vid. S. ARnoldsson, ob. cit., pág. 200 n. 38.

19 A. Castro: La realidad histórica de España, México, Porrúa, 1954, pág. 126.

20 Cf. el pasaje en la trad. de Fabié (n. 3). pág. 163. 
-dice- los verdaderos amos de España»--, pues con los Reyes Católicos había cambiado el panorama ${ }^{21}$.

Debido a que tales relatos quedaron inéditos o casi ignorados hasta el siglo XIX, no cabe suponer una acción de los mismos sobre la opinión alemana antes y después de Lutero. Como puntualiza Arnoldsson, «el interés que tienen para nosotros estos escritos hay que inferirlo de manera indirecta y nos explican qué concepto de España podían y solían tener los alemanes durante la época de 1450 a $1500 "{ }^{22}$. Es verosímil una idea general - a menudo falsa o equivocada - de las gentes peninsulares, semejante a la de los autores consignados, y puesta en circulación por anónimos mercaderes, turistas y peregrinos.

Algunos lugares comunes sobre los españoles pasarian al sabio cosmógrafo Sebastián Münster, en la primera mitad del siglo xVl; quien, por su parte, había leído y repetía, ora datos geográficos, ora juicios de valor acerca de Hispania, expuestos por el ilustre médico, humanista y reformador aragonés, Miguel Servet ${ }^{23}$.

\section{JÖRG VON EHINGEN: MILICIA Y AVENTURA}

El caballero suabo Jörg von Ehingen personifica la nobleza germánica ansiosa de aventura y, por tanto, de hazañas en nuevos escenarios bélicos o románticos. Su testimonio es, a la vez que una estimable autobiografía con datos genealógicos y sociales de relieve, una fuente digna de atención para la Península a mediados del siglo $x v y$, también, para la historia militar de Ceuka bajo dominio portugués ${ }^{24}$. Al servicio, primeramente, del conde del Tirol, Segismundo, y luego de Alberto de Austria, duque de Carintia y hermano del emperador Federico III, Jörg von Ehingen, para cumplir un ferviente anhelo de su padre Rudolfo — varón pia-

21 Cf. J. Mũnzer («Monetarius»): Viaje por España y Portugal, 1494-1495. Prólogo de M. Gómez Moreno. Trad. de J. López Toro. Madrid, Aldus, 1951, pág. 21.

22 S. ARNOLDSSON, ob. cit. (n. 16), pág. 114.

23 S. ARnOLDSSON, ob. cit., págs. 114-117.

24 Vid. las referencias bibliográficas, sobre este personaje, en la n. 3. 
doso y discreto- se embarcó en Venecia junto con los Comendadores de la Orden de San Juan, más otros caballeros de Francia y de los reinos hispánicos, dispuesto a luchar contra los turcos en Rodas. Al cabo de once meses despidióse del Gran Maestre y peregrinó a los Santos Lugares, donde sufriría algunos contratiempos, dirigiéndose entonces a Chipre y, por último, regresando a Suabia, donde su padre le acogió con gran alegría y orgullo. Tenía a la sazón veintisiete años, aproximadamente. Cuando se hallaba en la corte del duque Alberto, gozando de la paz reinante, hacia 1454 sintió nuevamente la imperiosa necesidad de correr aventuras: "Yo soñaba siempre - declara- conseguir con mis actos gran fama siguiendo mis ideas caballerescas, a fin de ser útil a los demás; y así pensaba que me sería conveniente recorrer los reinos más célebres de la Cristiandad, y permanecer ya en uno, ya en otro, hasta que pudiese ejecutar hazañas famosas y de peligro» ${ }^{25}$.

En compañía de otro caballero, Jorge de Ramyden, natural de Salzburgo, obtuvo cartas del rey Ladislao y hasta del emperador para los soberanos de Francia, Portugal, Castilla e Inglaterra; pero, una vez en Francia - decepcionados porque la corte de Carlos VII, ya viejo, no invitaba a ninguna empresa heroica-, ambos caballeros se enteraron de que Enrique IV de Castilla preparaba una incursión contra los moros de Granada en 1457, y decidieron sumarse a ella. Es así cómo Jörg von Ehingen inicia su «cruzada» peninsular: el relato ofrece interés para los reinados de Enrique IV y Alfonso $V$ de Portugal.

La entrada de Ehingen y su compañero en la Península fue por Navarra, donde se les comunicó que la expedición castellana contra el reino nazarí estaba de vuelta. Resolvieron, pues, tras una breve permanencia en la corte de Juan II, viajar a Portugal. Informados sobre las empresas africanas $y$, muy particularmente, del peligro que se cernía sobre Ceuta a causa de una alianza magrebí, emprendieron la marcha hacia el reino luso pasando antes por Santiago y embarcándose en Finisterre para Lisboa. El monarca les recibió cortésmente al tener noticia de quiénes eran, poniendo, además, a su disposición un intérprete brabanzón. Al manifestar a Alfonso $V$ su deseo de servirle militarmente en Ceuta, el rey aceptó, concediéndoles un descanso en medio de juegos y banquetes. Visitaron el país, donde pudieron apreciar sus riquezas naturales, sus ciudades, castillos y monasterios, sobre todo el de Batalha, erigido para conmemorar la victoria de Aljubarrota (1385). Desde alli y

${ }^{25}$ Cf. la trad. de Fabié (n. 3), pág. 24 (Se cita por Viajes...). 
equipados por el soberano portugués, navegaron rumbo a Ceuta, que ya estaba guarnecida por fuerzas listas a defenderla. El gobernador de la plaza le confió uno de los barrios o cuarteles, con soldados y caballeros «entre los cuales abundaban quienes comprendían y hablaban el idioma de la Baja Alemania» ${ }^{26}$, llevando a cabo misiones previas de reconocimiento por mar, a fin de calcular los efectivos musulmanes, que se comprobó eran poderosos. Muy precisa es la descripción que Ehingen hace de la plaza y de las medidas adoptadas para su defensa; también, ya producido el ataque, describe los combates en forma tan vigorosa, que los pasajes constituyen verdaderos aguafuertes. Al tercer día, convencidos los moros sitiadores de que no podían tomar Ceuta, resolvieron levantar el campo. «Entonces nosotros - dice-, con unos cuatrocientos caballos y mil infantes escogidos, decidimos perseguirles y aprovecharnos de su huida, pero muchas veces se revolvieron y pelearon con nosotros, hasta que nos apoderamos de uno de los cerros; pero los moros se habían posesionado de otro, y entre ellos y nosotros había un hermoso valle" ${ }^{27}$.

Es en este momento cuando tiene lugar el duelo entre un caballero musulmán y el suabo, a iniciativa mora, con el fin de dirimir la contienda. El pasaje, de recio carácter épico, nos presenta a Ehingen vencedor, con la decapitación de su adversario. "Cuando los moros vieron lo que yo había hecho, huyeron en el mayor desorden. Pero los portugueses... corrieron en busca mía, y se llevaron la cabeza del moro, se apoderaron de su lanza y lo despojaron de sus armas. Eran muy ricas y al estilo morisco, y hechas con gran maestría» ${ }^{28}$.

Alcanzado tan clamoroso triunfo, regresan a Portugal, donde el monarca les festeja, permaneciendo en el país siete meses más. Al llegarles, entre tanto, nuevas de Castilla sobre otra campaña organizada por Enrique IV contra el reino de Granada (estamos aún en 1457), ambos caballeros se ponen a su disposición e intervienen en las acciones. Ehingen exagera, sin duda, los contingentes cristianos (70.000 hombres) y las bajas causadas al enemigo ( 30.000 muertos); pero seguramente dice verdad cuando refiere que «nos vimos... en la necesidad de asaltar la mayor parte de las fortalezas y pueblos, y dar muerte a todos los moros, y los asistentes y demás servidores tenían también orden de pasar a cuchillo

${ }^{26}$ Viajes..., pág. 33. Sobre el Portugal de Alfonso V, vid. la tesis de M.N. DiAs: $O$ capitalismo monárquico portugués (1415-1549), 2 vols., Coimbra 1963-1964.

${ }^{27}$ Viajes..., pág. 37.

28 Viajes..., pág. 39. 
a las mujeres y a los niños, como lo hicieron " ${ }^{29}$. Durante más de un mes asolaron el reino nazarí: "el pueblo contra quien se combatía -reconoce- era muy esforzado" ${ }^{30}$. Nuestro caballero suabo quedó herido en una pierna, de por vida, a causa de un dardo. Ya en la Corte enriqueña se le otorgó el distintivo de las órdenes seglares, entre ellas la de la Banda ${ }^{31}$. Recibieron también ambos alemanes 300 ducados y sendos caballos, volviendo a Portugal, donde asimismo les obsequió el rey con ricos presentes, algunos de los cuales, $v$. gr. piezas de lujosas telas y varios corceles, vendieron -haciendo negocio- a su paso por Zaragoza y a través de Francia. Embarcáronse, finalmente, para Inglaterra. «El Rey - dice- nos concedió la entrada en todas su Ordenes de caballería. Mi compañero se separó de mí y yo me encaminé a Escocia. El Rey era hermano de la esposa de mi señor, y me recibió bien, y me trató espléndidamente ${ }^{32}$. No menos agasajado, pues, en esta corte que en las anteriores, Jörg von Ehingen concluye así su expresivo y sobrio relato.

Antonio M. ${ }^{a}$ Fabié dedicó en su "Introducción» páginas de gran interés a las miniaturas que adornan el Ms. de Stuttgart: son de valor iconográfico para los reyes Juan II de Navarra, Enrique IV de Castilla y Alfonso $\mathrm{V}$ de Portugal. Estudiadas por A. Vallet de Virville en el tomo XV de los "Annales archéologiques» - de cuyo artículo se hizo, en 1855, una tirada aparte que a fines del siglo XIX era ya una rareza bibliográfica-, tales retratos no parecen haber sido pintados del natural, pero el de Enrique coincide bastante con el de Alonso de Palencia en sus Décadas $\left(I, 1,2 .^{\circ}\right)^{33}$.

29 Viajes..., págs. 42-43. Para estas campañas y el reino nazarí en el marco políticocultural de la época, vid.: R. ARIÉ: L'Espagne musulmane au temps des Nașrides (12321492), Paris 1973. - L. SECO DE LuCENA PAREDES: La Granada nazarí del siglo XV, Granada, Patronato de la Alhambra, 1975.- M.A. LADERO QUESADA: Granada. Historia de un país islámico (1232-1571), Madrid, Gredos, 1969, págs. 107-115 (hay n. ed., 1979).- Sobre el reinado de Enrique IV, vid. L. SUÁREZ FeRnÁNDEZ: Los Trastámaras de Castilla y Aragón en el siglo Xv (1407-1474), en: Historia de España dirig. por R. Menéndez Pidal, t. XV, Madrid, E. Calpe, 1964, págs. 1-138. Es interesante, asimismo, T. MLLLeR: Henry IV of Castile, Londres, Gollanz, 1972.

${ }^{30}$ Viajes..., pág. 44.

${ }^{31}$ Cf. el notable estudio de L.T. VILlanueva: Memoria sobre la Orden de Caballería de la Banda de Castilla, "Boletín de la Real Academia de la Historia", LXXII (1918).

32 Viajes, pág. 46.

${ }_{33}$ Cf. G. MARAÑón: Ensayo biológico sobre Enrique IV de Castilla y su tiempo, 12 ed., Madrid, E. Calpe, 1975, págs. 75-83 (Colec. Austral, 196). E. ToRmo: Las viejas series icónicas de los Reyes de España, Madrid 1916. F.J. Sánchez CANTón: Los retratos de los Reyes de España, Madrid 1948. 


\section{EL HIPERCRÍTICO NICOLÁS DE POPPLAU}

Uno de esos caballeros centroeuropeos que recorrió la Península a fines del siglo $x v$ y que informa sobre Andalucía, Aragón y Cataluña emitiendo juicios discutibles, pero no exentos de gracia e interés en orden al carácter de las gentes, la economía y los ambientes cortesanos, es Nicolaus von Popplau o Popielovo, natural de la Silesia polaca (Wroclaw-Breslau) y miembro de un linaje bastante germanizado. Inteligente, jovial, imaginativo y proclive siempre a la aventura por su gran curiosidad y su animoso corazón, distinguíase, además, por su extraordinario vigor físico, puesto al servicio del Imperio bajo Federico III. Cansado, empero, de las armas, instruido en las humanidades clásicas - hablaba el latín con soltura-, decidióse a viajar rumbo al Occidente y al Sur. Visitó, en consecuencia, Baviera y las ciudades de Heidelberg, Coblenza, Bonn, Colonia, etc., los Países Bajos y Londres en tiempo de Ricardo III. A Portugal llegó embarcado el 5 de junio de 1484, y a Compostela el 21.

El relato de sus viajes entre los años 1483 y 1486, compuesto en alemán, lo conocemos por una copia que se conserva en la antigua Biblioteca de Santa Isabel, de Lvov (en polaco, Lwow; en alemán, Lemberg), publicada a comienzos del siglo pasado (1806) y que el profesor de aquella Universidad, J. Liske, divulgó en un documentado libro ${ }^{34}$. « $\mathrm{Ni}$ colás - según Liske - escribe con energía, sus observaciones no carecen de criterio, dice siempre la verdad como él la entiende, y sin exageración; su estilo es sencillo, y algo alegre y rústico embellece sus cuentos y lleva al lector a creer que está presente él mismo a las escenas que su autor pinta.... ${ }^{35}$.

Nicolás salió mal impresionado de Galicia y Portugal. No puede ocultar sus aciagas experiencias: «Incapaces de buenas costumbres -refunfuña-, y esto a pesar de su pretensión de ser los más sabios; como los ingleses, que no admiten otro mundo igual al suyo» ${ }^{36}$.

34 Vid. la n. 3. Un resumen, con extractos, en Garcia MERCADAL, ob. y vol. cits., págs. 199-210.

35 J. LISKE, ob. cit., pág. 12.

36 Ob. cit., pág. 26. Cf., entre otras exposiciones, A. Collantes de Terán: Sevilla en la Baja Edad Media. La ciudad y sus hombres. Sevilla 1977. 
También en el reino de Castilla sintió más de una frustración y hasta enojo, porque los oficiales cercanos a la Corte, en Sevilla, le hicieron aguardar durante un mes la audiencia real, pensando aquéllos, seguramente, que estaba allí para solicitar favores: «Este procedimiento -critica- de regatear el honor y la majestad de un Rey es muy vergonzoso, porque de ahí nace luego la humillación, y aunque no me hubiese propuesto jamás pedir algo al Rey, se hubiera debido tener en consideración que soy un viajero extranjero, que con peligro de mi vida y fortuna atravesé tantos reinos, para que pudiera ver también a este Monarca, y rendirle el homenaje debido ${ }^{37}$. ¿Esperaban, por otra parte, los celosos intermediarios que él se mostrase pródigo en dádivas con ellos?

Al fin, gracias a un embajador de Borgoña, Fernando el Católico le recibió dignamente, obsequiándole incluso con largueza, pues le envió a la posada, "para cubrir mis gastos la cantidad de cien doblones, de valor de un ducado y medio cada uno, y al mismo tiempo me regaló dos corceles ${ }^{38}$. La Reina Isabel no parecía, sin embargo, tan bien dispuesta hacia él como su esposo; "porque - añade - trayendo cartas del Emperador y del duque de Burgundia para el Rey, no tenía ninguna para ella» ${ }^{39}$. Descubre así el "Tanto monta...", que no acaba de comprender en su mecánica gubernamental: «Es preciso hacer constar aquí -se pasma - un contrasentido de aquel reino, en que la Reina es Rey, y el Rey es su servidor" ${ }^{40}$.

El 24 de diciembre de aquel año, 1484, asistió en Sevilla a una ceremonia conmemorativa - anualmente - de la entrada de Fernando III en la ciudad. "Apercibí entonces en la procesión - dice- que el Rey es servidor de la Reina, porque lo llevaba a su derecha, y al Cardenal a su izquierda; y tanto es así, que la nobleza teme más a la Reina que al Rey, que en todos sus instantes no se preocupa de otra cosa que de cumplir las órdenes, mandas y voluntades de la Reina... Lo que se decide entre el Cardenal... y la Reina, el Rey ha de ejecutarlo. Por este motivo se murmura mucho en Aragón contra el Cardenal...; y si se publica alguna orden en dichos países por el Rey o por el Cardenal, no hacen caso; mas tiemblan al nombre de la Reina ${ }^{41}$.

\footnotetext{
J. LISKE, ob. cit., pág. 44.

Ob. cit., pág. 45.

lbidem.

Ob. cit., págs. 46-47.

Ibidem.
} 
Respecto a los judíos, los conversos y la «protección» que les dispensa la Reina, según Nicolás de Popplau, éste afirma categóricamente: "Yo también observé con mis propios ojos que tiene más confianza en los judíos bautizados, que en los cristianos»... «En sus manos -añadeentrega todas sus rentas y censos; son sus consejeros y secretarios, como también lo son del Rey, y sin embargo, en vez de respetarlos, más los odian que otra cosa" ${ }^{42}$.

El caballero germano-polaco, aunque bien tratado por el Rey, se formó una pobre opinión de los cortesanos: «Puedo decir, en honor de la verdad, que no he visto ni encontrado nunca en ninguna parte gente tan necia e impertinente como aquí. Si alguno de ellos estuvo una sola vez en Roma, se figura que posee la sabiduría del mundo, o que le ha visto entero" ${ }^{43}$. Hasta el clero, según él, hablaba latín deficientemente; pero incurre, a propósito de Córdoba, en un craso error histórico suponiéndola cuna de Tito Livio y de Valerio Máximo. Lo único agradable de su estancia en Andalucia es algo tan simple como el delicioso pan de Sevilla. Reconoce, eso sí, que Granada esta pobladísima y celebra la fertilidad de Jerez de la Frontera.

Tampoco sale bien parada Burgos, cuya importancia se reduce a que «es una plaza de mercado de las mejores mulas: de allí las llevan a Portugal, Aragón, Cataluña, a toda España, a Italia, Roma y también a Francia...»"

En los Estados de la Corona de Aragón observa que los puertos de la Real Aduana se hallaban ocupados por judíos, "tanto en las ciudades y puertos de mar como en todo el resto del reino, y no obstante las Reales cartas que me autorizaban el paso libre, se me exigian, sin embargo, dos ducados, y para no pagarlos acudí al juez...» ${ }^{45}$, quien le eximió de los impuestos.

De Valencia le sorprende su relativa autonomía: "un país particular con su Gobierno, que hasta de las órdenes del Rey poco caso hace...» Y también la hospitalidad de sus gentes: «me presentaban algunas veces

42 Ibidem. Cf. Y. BaER: Historia de los judios en la España cristiana, trad. espñ., vol. Ii, Madrid, Altalena, 1981, págs. 556-564.

43 J. LISKE, ob. cit., pág. 48.

44 Ob. cit., pág. 49.

45 Ob. cit., págs. $52-53$. 
- consigna divertido- a sus señoras, que yo por galantería, y en la presencia de ellos, tenía que tomar en mis brazos y darles besitos» ${ }^{46}$. Asimismo le llama gratamente la atención la cerámica que los artesanos mudéjares fabrican, con primor, en Manises y Paterna, exportándola a todos los países. No cabe duda de que Valencia le gusta más que otras ciudades, si bien - coincidiendo con los demás alemanes- se refiere a los "sarracenos" o mudéjares en términos muy peyorativos, sin comprender, obviamente, la coexistencia social y económica de cristianos, judíos y musulmanes. Toma nota de la moral laxa dondequiera que va; libertinaje, a su juicio, muy extendido en la Península.

Junto con los cuadros o bocetos costumbristas, no omite la información agrícola, ganadera y comercial, aunque en forma demasiado sumaria; pero de algún interés respecto al vino (sostiene que los caldos portugueses son superiores a los andaluces), el trigo (exportado desde Andalucia a Portugal, Galicia, Aragón y Cataluña, mas no a Castilla, porque ésta «lo tiene de sobra»), el aceite, los cítricos, los higos, las moreras, la caña de azúcar, etc. (del reino de Valencia, especialmente), y, en Ibiza, «la más hermosa y blanca sal que yo he visto" ${ }^{47}$.

En Cataluña - que «está llena de desiertas montañas", dice, «y por esta razón se paga todo allí muy caro"- elogia el monasterio de Poblet, «en que todo abunda», y el de Montserrat, donde «la Virgen María hace grandes milagros" ${ }^{48}$. Por fin arriba a Barcelona el 17 de enero de 1485, día de San Antonio Abad. «Barcelona - se lamenta - no me obsequió, porque desprecia las cartas y sellos de su Rey, y me cargó más en su aduana que a cualquiera otro" ${ }^{49}$, pese a haber mediado el Virrey. La emprende, pues, contra el sentido crematístico de la vida que, según él, mueve a sus habitantes. Añade que los campesinos «premeditan una sublevación contra los señores y caballeros para sujetarlos de este modo a la obediencia de su soberano ${ }^{50}$. Entre los malos usos de la vida rural menciona el ius primae noctis.

46 Ob. cit., pág. 54. A propósito de las valencianas, cf. las observaciones de Jerónimo Münzer (trad. cit., n. 21), págs. 22-23.

47 J. LISKE, ob. cit., pág. 60. Cotéjese también con J. Münzer (n. 21), sobre la riqueza del Levante, págs. 18-20 y 22-24. Un buen trabajo reciente es el de GuIRAL-HADZIIOSSIF: Valence, port méditerranéen au XVe siècle (1410-1525). Paris, 1987.

48 J. LISKE, ob. cit., pág. 61.

49 Ob. cit., pág. 62. Cf. Jerónimo Münzer (n. 21), págs. 9-13.

so Ob. cit., págs. 63-64. 
De todos modos, las barcelonesas le encantan: «Si se pueden encontrar hermosas mujeres en todas partes de España -afirma-, por cierto las hay más aquí que en cualquier otro lugar; pocas se pintan, parece que los tarritos de colores concluyen en esta ciudad» ${ }^{51}$.

Nicolás de Popplau o Popielovo abandona la Península, no sin comentar que los reyes de Aragón y Portugal «están siempre espiándose para despojarse recíprocamente, sin preocupación de medios lícitos, y eso únicamente por la maldita envidia, de que ambos de distinguen entre todos los demás reyes del mundo" ${ }^{52}$; censurando, por último, la deslealtad y aun perjurio de sus súbditos.

Regresó por Francia y Alemania a su tierra natal en el año 1486; pero en septiembre del mismo, habiéndose decidido a peregrinar a Jerusalén, emprendió su viaje a la eternidad en el puerto de Alejandría.

\section{ARNOLD VON HARFF Y JACOBSLAND}

Un coetáneo de Nicolás, que peregrinó a Santiago legándonos sus impresiones del viaje, es el noble renano Arnold van Harff, quien, a los veinticinco años y en 1496, volvía de Egipto y del Sinaí, tras una escala veneciana ${ }^{53}$. Su itinerario constituye un valioso testimonio, ya por las noticias precisas que da como por el tono crítico acerca de los caminos, puentes, peajes, alojamiento y, desde luego - una vez en Compostela-, sobre el culto jacobeo en su abigarrado marco urbano. Evidentemente, como dice L. Vázquez de Parga, «sus disposiciones en el piadoso viaje no iban encaminadas únicamente a la devoción ${ }^{54}$.

Arnold von Harff se queja, por ejemplo, de las exacciones que, por derechos de peaje, debió sufrir en Navarra; "lo cual -anota- me parece muy abusivo, pues no he encontrado ninguna aduana de este género ni

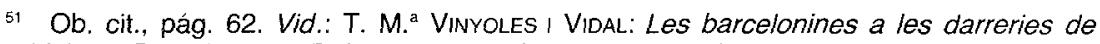
I'Edat Mitjana, Barcelona, R. Dalmau, 1975, págs. 189-211, y La vida quotidiana a Barcelona vers 1400, Barcelona, R. Dalmau, 1985, págs. 189-211.

52 Ob. cit., pág. 64.

53 Vid. ก. 3.

54 L. VázQuez de Parga, ob. y vol. cits. (n. 3), pág. 229. 
en la Cristiandad ni en los países musulmanes» ${ }^{55}$. Respecto a las posadas, aumenta su malhumor: "Desde Orthez (en los Bajos Pirineos) hasta Santiago no hay una sola etapa buena para ti ni para tu caballo. Si quieres comer o beber, tendrás solamente lo que compres por el camino, y no hallarás ni avena ni paja para tu caballo. Además, has de dormir en el suelo y alimentarte de cebada" ${ }^{56}$. Bastante desilusionado, concluye: «Summa summarum, is Hyspanien gar eyn buesser lant» (En suma, España es un país bien malo). Comete algún que otro error hagiográfico (por ejemplo, confundir el cuerpo de Santo Domingo de la Calzada con el de Santo Domingo de Guzmán); pero, en general, sus observaciones son certeras e incluso de gran interés para la geografía, costumbres y mentalidad social, no menos que para la historia urbana. Evoca el sombrío espectáculo de las horcas extramuros de las poblaciones, con los ejecutados a la vista del viandante, y revela inquietudes lingüísticas.

Cuando llega, por fin, a Santiago, su primer impulso es rogar que le dejen ver el cuerpo del Apóstol: «Yo traté con grandes ofertas - dicede que se me enseñase el santo cuerpo. Se me contestó que no se acostumbraba hacerlo; que el cuerpo santo de Santiago está en el altar mayor, y que el que dudase de que fuese su cuerpo, en el mismo momento se volvería loco como un perro rabioso. Con esto me bastó, y fuimos a la sacristía, donde nos enseñaron la cabeza de Santiago el Menor y otras muchas reliquias» ${ }^{57}$. Por último, su a medias candorosa e irónica alusión a la venera: "Delante de la iglesia verás innumerables conchas, grandes y pequeñas, que debes comprar y ponerte en el sombrero para hacer ver que has estado allá...” ${ }^{58}$.

55 Cit. por P. Barret-J.N. Gurgand: Priez pour nous à Compostelle. Préface de R. de la Coste-Messelière, Paris, Hachette, 1978, pág. 103.

56 Cf. L. VázQuez de PARGa, ob. y vol. cits. (n. 3), pág. 228.

57 Ob. cit., págs. 229-230. Cf. Jerónimo Münzer (n. 21), pág. 82.

58 L. VÁzQUEZ DE PARGA, ob.y vol. cits., pág. 230. Sobre Galicia y, concretamente, Santiago entonces, vid.: A. LóPEz Ferreiro: Historia de la Santa A. M. Iglesia de Santiago de Compostela, vols. II-IX, Santiago 1907, y Galicia en el último tercio del siglo xv, 3. ${ }^{a}$ ed. Vigo 1968. J. PorTela Pazos: Galicia en tiempo de los Fonseca, Madrid, 1957. Agradezco a don Iñaki Múgica haber atraído mi atención, cuando este artículo estaba ya redactado y entregado a la imprenta, sobre el libro, muy notable y que no conocía, de Eneko MiTXELENA: Viajeros extranjeros en Vasconia, Buenos Aires, Editorial Vasca EKIN, s. a. En él Arnold von Harff ocupa las páginas 57-70, con muy interesantes observaciones acerca del personaje durante su estancia en el País Vasco, sobre todo su curiosidad por la lengua (págs. $62-63$ y 66-68) y las frases de requiebro a las bellas mozas. 
